\title{
Preparing the ground for an operational handling of long-term emissions in LCA
}

\author{
Bakas, loannis; Hauschild, Michael Zwicky; Astrup, Thomas Fruergaard; Rosenbaum, Ralph K.
}

Published in:

International Journal of Life Cycle Assessment

Link to article, DOI:

10.1007/s11367-015-0941-4

Publication date:

2015

Document Version

Peer reviewed version

Link back to DTU Orbit

Citation (APA):

Bakas, I., Hauschild, M. Z., Astrup, T. F., \& Rosenbaum, R. K. (2015). Preparing the ground for an operational handling of long-term emissions in LCA. International Journal of Life Cycle Assessment, 20(10), 1444-1455. https://doi.org/10.1007/s11367-015-0941-4

\section{General rights}

Copyright and moral rights for the publications made accessible in the public portal are retained by the authors and/or other copyright owners and it is a condition of accessing publications that users recognise and abide by the legal requirements associated with these rights.

- Users may download and print one copy of any publication from the public portal for the purpose of private study or research.

- You may not further distribute the material or use it for any profit-making activity or commercial gain

- You may freely distribute the URL identifying the publication in the public portal 
Cite as Bakas, I., Hauschild, M.Z., Astrup, T.F., Rosenbaum, R.K.: Preparing the ground for an operational handling of long-term emissions in LCA. International Journal of LCA 20(10), 1444-1455, DOI10.1007/s11367-015-0941-4, 2015.

\section{Preparing the ground for an operational handling of long-term emissions in LCA}

2 Ioannis Bakas ${ }^{* 1}$, Michael Z. Hauschild ${ }^{1}$, Thomas F. Astrup ${ }^{2}$, Ralph K. Rosenbaum ${ }^{3}$

$3 \quad{ }^{1}$ Division for Quantitative Sustainability Assessment, Department of Management Engineering, Technical

4 University of Denmark Kgs. Lyngby, DK-2800

$5 \quad{ }^{2}$ Department of Environmental Engineering, Technical University of Denmark, Kgs. Lyngby, DK-2800

$6{ }^{3}$ Irstea, UMR ITAP, ELSA-PACT - Industrial Chair for Environmental and Social Sustainability Assessment, 361

7 rue Jean-François Breton, BP 5095, F-34196 Montpellier Cedex 5, France

8 KEYWORDS: LCA, landfill, heavy metals, long-term, toxicity.

\section{ABSTRACT}

10 Purpose. Currently, there is no meaningful methodology for the estimation of environmental impacts from long11 term heavy metal emissions in a Life Cycle Assessment (LCA) context, when an assessment of landfill and mining 12 technologies is performed. In this paper, the aim is to investigate the main issues hindering the standardization of a 13 methodology to account for potential impacts from long-term metal emissions, and to describe the characteristics of 14 a robust framework for an operational impact assessment methodology.

15 Methods. In order to demonstrate the issues around potential impacts from long-term emissions in LCA and derive a 16 scientific basis for developing an adequate LCA methodology to address these impacts, a two-part review on metal 17 long-term emissions is performed that a) identifies a suitable time-dependent Life Cycle Inventory (LCI) while 18 underlining the problems in existing emission prediction attempts and b) describes the existing LCA approaches for 19 accounting for toxic potential impacts from these emissions, while explaining the reasons that the identified 20 proposals have not been adopted from the LCA community. These approaches are then compared upon the basis of a 21 common LCI and their differences are highlighted.

\footnotetext{
*e-mail: ioba@dtu.dk
} 
Cite as Bakas, I., Hauschild, M.Z., Astrup, T.F., Rosenbaum, R.K.: Preparing the ground for an operational handling of long-term emissions in LCA. International Journal of LCA 20(10), 1444-1455, DOI10.1007/s11367-015-0941-4, 2015.

22 Results. A suitable dynamic LCI is identified for landfill emissions, which calculates Ni, Zn, Cd and Pb emissions as

23 a function of time, based on assumed developments of the leachate $\mathrm{pH}$. The results of the application of the different

24 impact assessment methods on that LCI differ by up to 8 orders of magnitude. Therefore, the decision- making

25 process supported by an LCA becomes very confusing. None of the approaches consider future changes in the

26 receiving environment and are not accompanied with any uncertainty considerations.

27 Conclusions. In order to move towards a robust environmental assessment of long-term emissions, it is necessary to

28 (i) represent future potential impacts more accurately by estimating time dependent CFs corresponding to changing

29 environmental conditions, (ii) develop more robust estimations by addressing uncertainty and (iii) refer to actual

30 potential impacts, by taking into account the current and future background concentrations.

\section{I INTRODUCTION}

32 Life Cycle Assessment (LCA) is a decision-support tool aiming at assessing the environmental impacts associated

33 with products or systems (ISO 2006a; ISO 2006b). An important element of LCA is the quantification of emissions,

34 representing an environmental exchange between the product or system and the ecosphere, and the subsequent

35 characterization of the emissions into potential environmental impacts by applying characterization factors (CFs) to

36 the emissions. LCA is widely used in decision-making processes in waste management by assessing integrated

37 waste management systems or comparing different alternatives for treatment of waste (Laurent et al. 2013a; Laurent

38 et al. 2013b). Contrary to product LCA, waste LCA focuses only on the end-of-life stage of products’ life cycles. In

39 waste LCA, the technologies involved are relatively limited (corresponding to a chain of waste treatment facilities).

40 The main direct emissions are thus typically caused by a few installations, the location of which is easier to identify

41 as well as the conditions of the receiving environment. This implies that a more site-specific approach is possible,

42 taking into account the local conditions in contrast to the typical situation for product LCAs. A site-specific

43 assessment is also highly relevant in the case of landfills, where the most important leachate impacts are expected to

44 be on a local scale (i.e. within a few $\mathrm{km}^{2}$ ).

45 Landfilling of waste (from e.g. households, industrial sites, institutions, construction and demolition sites,

46 etc.) constitutes a predominant waste treatment technology globally. However, landfill leachate poses an important

47 environmental concern. The leachate composition has been well investigated for many types of landfills and its

48 heavy metal content comprises one of the major environmental pollutants in waste management (Christensen et al. 
Cite as Bakas, I., Hauschild, M.Z., Astrup, T.F., Rosenbaum, R.K.: Preparing the ground for an operational handling of long-term emissions in LCA. International Journal of LCA 20(10), 1444-1455, DOI10.1007/s11367-015-0941-4, 2015.

49 2001). Besides toxicity, a problematic property of metals is their environmental persistence, which is practically

50 infinite and thus far superior to any organic chemical. In an LCA context, the toxicity potentials of heavy metal

51 emissions have hence been estimated as relatively high compared to other compounds (Huijbregts et al. 2000).

52 Given the high toxic potential, an accurate representation of potential impacts from landfill metal leaching in LCA is

53 essential to ensure the credibility of the tool in assisting informed decision-making, neither ignoring nor

54 overestimating their importance.

55 When trying to estimate the impacts from landfilling in an LCA context, an important characteristic of

56 landfill metal emissions is the very long time horizon of thousands or even hundred thousands of years over which

57 their release takes place in contrast to the other processes in the system which typically emit within minutes to days.

58 The widely used Ecoinvent inventory database defines long-term metal emissions as occurring after 100 years until

5960000 years from now (“until the next plateau-covering glacial period [in Switzerland] is estimated”) (Hischier et al.

60 2010). During this period small amounts of leachate or run-off containing pollutants (especially heavy metals) are

61 emitted from the landfill to the surrounding soil, aquifer, and eventually the surface water.

Apart from leachate from landfills of municipal, inert or hazardous waste, long-term heavy metal emissions

63 can be found in the tailings from mining operations leading to significant environmental burdens (Stüben et al.

64 2001) that are not properly addressed in LCA mainly due to the lack of reliable data (Althaus and Classen 2005) and

65 an appropriate impact assessment methodology. This problem has been underlined and investigated through a

66 sensitivity study that showed the strong dependence of LCA results from mine tailing management on the choice of

67 time frame (Reid et al. 2009). Also the management of radioactive waste can cause long-term leaching of metals

68 (Singh and Hendry 2012), but due to the special properties of radioactive waste, this source of heavy metal

69 emissions is not investigated in this paper, although some of the considerations described below could be relevant.

70 Out of the leachate pollutants from landfills, long-term metal emissions constitute a particularity in the

71 LCA context. Inventory modelling in LCA applies a time-integration principle, according to which all emissions

72 should be treated as a pulse emission occurring at one point in time, whether they in reality occur in different parts

73 of a life cycle or extended over long-time periods (Guinée and Heijungs 1993). The latter case poses problems when

74 emissions occur in relatively low concentrations over very long time periods leading to large cumulated pulse flows.

75 Their impacts are potentially overestimated when the resulting impact scores from emissions in low concentrations

76 integrated over tens of thousands of years, are interpreted in the same way as impact scores for emissions occurring 
Cite as Bakas, I., Hauschild, M.Z., Astrup, T.F., Rosenbaum, R.K.: Preparing the ground for an operational handling of long-term emissions in LCA. International Journal of LCA 20(10), 1444-1455, DOI10.1007/s11367-015-0941-4, 2015.

77 in significantly shorter periods and thus integrated over shorter periods of time which is the case for transportation

78 processes and many industrial processes. There is a "dilution in time” which is important for the observable impacts

79 from the long-term emissions but not represented in the calculated potential impacts in life cycle impact assessment

80 (LCIA).

81 In LCIA toxic impacts are modelled using steady-state conditions, applying integration over a defined time

82 horizon. Integrating the potential impacts of long-term emissions over a relatively short time horizon like 100 or 500

83 years (as done for e.g. Global Warming Potentials), and thus neglecting impacts from emissions occurring later,

84 potentially leads to an underestimation of their impacts. On the other hand, including them fully through integration

85 over very long or even infinite time horizons would lead to a strong overestimation, as the (perhaps negligible if

86 from very low emission concentrations) potential impacts occurring over a long period of time would be fully

87 attributed to the product as if they were occurring right now (as one large emission) in the same way as an emission

88 from e.g. a waste incinerator. While the latter approach does not account for the "dilution in time” of the impact, the

89 first approach completely neglects the long-term potential impacts. These two extremes present a dilemma for which

90 an operational and accurate solution is needed in LCIA. Some LCIA approaches specifically deal with long-term

91 emissions (Pettersen and Hertwich 2008; Hauschild et al. 2008). However, currently there is no consensus among

92 researchers on a common methodology, which is illustrated by the differences in this perspective of the various

93 LCIA methodologies (Hischier et al. 2010). Moreover, there are no characterization factors available for long-term

94 emissions of metals, which thus have to be represented by the generic characterisation factor for the metal. Further

95 research is called for so that a more accurate representation of long-term emissions is achieved (Hischier et al.

96 2010).

97 In summary, when attempting to integrate this kind of emissions and their potential impacts into an LCA,

98 two main hurdles need to be overcome: 1) estimating/predicting the future emissions in the inventory phase, and 2)

99 characterising the emissions in a meaningful way that puts them into perspective relative to the impacts caused by

100 emissions that occur over a much shorter time. In order to better understand the perspectives for an adequate

101 representation of long-term emissions, a consistent overview of past experience and current practice within the LCA

102 field is needed. This is done through (i) reviewing the status, reliability and common ground of emission prediction

103 methodologies from an LCA perspective, (ii) reviewing the current proposals for characterization of long-term

104 emissions in LCIA, comparing them in terms of the results they provide, and based on that (iii) derive main 
Cite as Bakas, I., Hauschild, M.Z., Astrup, T.F., Rosenbaum, R.K.: Preparing the ground for an operational handling of long-term emissions in LCA. International Journal of LCA 20(10), 1444-1455, DOI10.1007/s11367-015-0941-4, 2015.

105 principles for a scientifically robust framework for an operational impact assessment for potential impacts of long106 term emissions in the LCA context.

\section{METHODOLOGY}

For addressing the aforementioned objectives, a literature review is conducted. Central studies are presented which have been published in peer reviewed journals and that address the issue of long-term emissions from landfills.

The first part of the review aims at identifying studies mainly within the waste management field, which

111 can provide a time-dependent life cycle inventory (LCI) for long-term metal emissions from landfills. A

112 scientifically sound study that provides metal emission profiles for $\mathrm{Ni}, \mathrm{Cd}$, Zn, and Pb, suitable as an input to an

113 LCI, is selected. The emission profiles correspond to the leaching of these metals from an air pollution control

114 residues (APCR) landfill of a total capacity of 1,000,000 tonnes.

115 The second part maps research within the LCA field to identify the various approaches that have been 116 developed to address the challenges is assessing potential impacts from heavy metals emitted in low quantities but

117 over long periods of time. The review illustrates the current state of the art and analyzes the existing approaches in 118 terms of the perspectives they adopt on future emissions.

119 The results from the two parts of the literature search are combined to form a case study where the different LCA 120 approaches are applied on a selected emission profile of a metal leaching out of an APCR landfill over a long time 121 period. The same CF (or comparative toxicity potential) is used for both short- and long-term emissions, adopted 122 from recent literature which estimates CFs for $\mathrm{Ni}$ and $\mathrm{Cu}$ with respect to terrestrial ecotoxicity (Owsianiak et al. 123 2013). The CF for Ni is chosen as an emission profile for Ni can be found in literature (Astrup et al. 2006). The 124 available CF is relevant for terrestrial ecotoxicity impacts, but from a nickel emission to air. Thus this CF is 125 corrected for emissions directly to soil using USEtox (Rosenbaum et al. 2008) and the resulting CF is $4.86 \mathrm{x} 10^{3}$ $126 \mathrm{~m}^{3} / \mathrm{kg}_{\text {emitted to soil }} \mathrm{x}$ day. Based on a common emission profile and an identical CF, the existing LCIA approaches can be compared

128 on the same basis. The time dependent emission profile for Ni provides emission quantities per 200 years time steps.

129 This quantity is integrated over 100 years (the first time step is divided in two) and over an infinite time horizon, and 130 the potential impacts in each case are then estimated by multiplying with the CF. The difference between the 131 impacts from the 100 years integration and the infinite time horizon is the impact allocated to a separate impact 
Cite as Bakas, I., Hauschild, M.Z., Astrup, T.F., Rosenbaum, R.K.: Preparing the ground for an operational handling of long-term emissions in LCA. International Journal of LCA 20(10), 1444-1455, DOI10.1007/s11367-015-0941-4, 2015.

132

133

134

135

136

137

It is also assumed that: future damage. soils is estimated at $16 \mathrm{mg} / \mathrm{kg}$ (Lado et al. 2008). This is used to estimate the background Ni dissolved concentration by using the equations below and the $\mathrm{K}_{\mathrm{dNi}}(280 \mathrm{l} / \mathrm{kg})$ default values found in the USEtox ${ }^{\mathrm{TM}}$ multimedia toxicity model (Rosenbaum et al. 2008):

The impact is then estimated per time step and discount rates of $\pm 0.01 \%$ are applied to future potential impacts. The magnitude of the rates is set to $0.01 \%$ as this is shown to correspond to time horizons of up to 100,000 years (Hellweg et al. 2003). One positive and one negative discount rate are modelled, in order to account for uncertainties regarding future economic development which determines the level of the compensation required for are compared to the European median background concentration of $\mathrm{Ni}$ in soils. The median situation is chosen for demonstrative reasons, but it is not recommended as the background concentrations for metals vary greatly geographically and according to soil types (Zhao et al. 2007). The median Ni extractable concentration in European

$$
C_{\text {total }}=C_{\text {sorbed }}+C_{\text {dissolved }}
$$

where $\mathrm{C}_{\text {sorbed }}\left(\mathrm{mg} / \mathrm{kg}_{\text {soil }}\right)$ is the sorbed metal concentration, $\mathrm{C}_{\text {dissolved }}$ is the dissolved metal concentration $\left(\mathrm{mg} / \mathrm{kg}_{\text {soil }}\right)$ and $\mathrm{C}_{\text {total }}$ is the extractable metal concentration ( $\left.\mathrm{mg} / \mathrm{kg}_{\text {soil }}\right)$. $\mathrm{C}_{\text {dissolved }}$ is converted into $\mathrm{mg} / \mathrm{l}$ by using the soil bulk density $\rho_{\text {bulk }}(\mathrm{mg} / \mathrm{l})$ and the soil water content $\mathrm{w}(\% \mathrm{v} / \mathrm{v})$ :

$$
C_{\text {dissolved }}\left[\frac{\mathrm{mg}}{\mathrm{l}}\right]=\frac{\rho_{\text {bulk }} C_{\text {dissolved }[\mathrm{mg} / \mathrm{kg}]}}{1000 \mathrm{w}}
$$

151 By combining the above equations, $\mathrm{C}_{\text {dissolved }}$ can be calculated as:

$$
C_{\text {dissolved }}\left[\frac{m g}{l}\right]=\frac{C_{\text {total }}}{K_{d}+\frac{1000 w}{\rho_{\text {bulk }}}}
$$


Cite as Bakas, I., Hauschild, M.Z., Astrup, T.F., Rosenbaum, R.K.: Preparing the ground for an operational handling of long-term emissions in LCA. International Journal of LCA 20(10), 1444-1455, DOI10.1007/s11367-015-0941-4, 2015.

152 The median global bulk density for soils, based on more than 15,000 samples is estimated at $1.4 \mathrm{t} / \mathrm{m}^{3}$ (Batjes 2008 )

153 and it is assumed to apply for Europe. The water content value is adopted from the USEtox default value, which is

154 0.2. Therefore, the dissolved median Ni concentration in European soils is estimated at $0.038 \mathrm{mg} / \mathrm{l}$.

155 Only the Ni concentration that is above the background level is transformed into mass and integrated over 156 time, then multiplied with the CF for $\mathrm{Ni}$ in order to provide the total actual potential impact.

157 A comparative analysis of the results of the application of the various LCA approaches helps identify the 158 effect that the specific assumptions and perspectives of each approach have on LCA results, thus directly affecting 159 decisions supported by waste LCA. Based on the analysis, a listing is made of the requirements for developing a

160 robust, common framework for addressing long-term emissions in LCA, by combining different characteristics of 161 the existing approaches.

3 MODELLING LONG-TERM EMISSIONS OF HEAVY METALS

163 Different types of landfills have been investigated in terms of pollutant release from the leachate. Inert landfills such

164 as an APCR landfills tend to be investigated more regarding metal emissions (e.g. Hellweg et al. 2005), while

165 landfills richer in organic matter are normally investigated in terms of organic pollutants (e.g Kjeldsen et al. 2002).

166 Long-term metal emissions are present in all types of landfills but the primary focus for toxicity might change with

167 landfill type. Also the waste composition in the landfill influences the pattern of metal emissions (Bolton and Evans 168 1991). The literature review conducted here is not confined to a specific landfill type in order to be comprehensive 169 and with the overall aim at identifying a time-dependent leachate inventory.

Heavy metal concentrations in landfill leachate have been extensively monitored and simulated in batch

171 tests for a surveyable time period, usually capped at 100 years (Finnveden et al. 1995; Flyhammar et al. 1998;

172 Kjeldsen and Christophersen 2001). A review of published monitoring and testing results concludes that the leachate 173 metal concentrations within such a short time frame do not pose a great environmental risk (Kjeldsen et al. 2002).

174 This observation fits well with the generally accepted assumption that typically the vast majority of the landfilled

175 waste content of heavy metals remains in the landfill 100 years after the waste deposition (Hauschild et al. 2008).

176 The heavy metal retention in landfills can be explained by mechanisms such as sorption and precipitation (Kjeldsen 177 et al. 2002).

178 On the other hand, the long-term heavy metal concentration in leachate is difficult to predict in a solid way 
Cite as Bakas, I., Hauschild, M.Z., Astrup, T.F., Rosenbaum, R.K.: Preparing the ground for an operational handling of long-term emissions in LCA. International Journal of LCA 20(10), 1444-1455, DOI10.1007/s11367-015-0941-4, 2015.

179 as laboratory simulation is not possible and mathematical models hence cannot be validated for time frames as long

180 as 100,000 to 250,000 years and should, therefore, not be over-interpreted (Finnveden et al. 1995). Theoretically,

181 after the stable methanogenic phase of a landfill rich in organic matter, the oxygen intrusion facilitates metal

182 mobility due to decreasing pH and oxidation to more soluble metal species (Christensen et al. 2000; Bozkurt et al.

183 2000). However, existing experimental work leads to contradictory results even for the medium time frame

184 (Kjeldsen et al. 2002).

Given the importance of oxygen intrusion on the landfill chemistry, a modelling approach has been developed based on the oxygen effect (Bozkurt et al. 2000). In order to predict future heavy metal concentrations in

187 the leachate, this model is based on the fact that, after the methanogenic phase of an organic landfill is completed,

188 the subsequent humic phase is characterized by much slower organic carbon degradation which means that oxygen diffuses into the landfilled waste (Bozkurt et al. 2000). The conceptual model is based on an analysis of the main

190 processes governing each landfill phase after the methanogenic phase, with the presence of oxygen considered as the 191 determining factor for metal mobility (Bozkurt et al. 1999).

Bozkurt et al. modelled several scenarios in order to determine the total depletion time for organics and metals in the waste mass and the influence of factors such as the type and characteristics of the top cover (Bozkurt et al. 2001). However, no results are presented regarding the quantity of heavy metals leaching out of the landfill as a function of time. Therefore, this work is not suitable for compiling an LCI.

Finnveden attempted to produce emission rates for metals contained in a municipal waste landfill based on a collection of mass balance approaches from literature (Finnveden, 1996). The author produced best estimates of emission rates for a surveyable time period (about one century from waste deposition), which may constitute a dynamic LCI. However, the mass balance approach for an infinite time frame, which is in line with the scope of this paper, claims that all metals will eventually leave the landfill. Therefore, this study does not provide a suitable timedependent LCI. 
Cite as Bakas, I., Hauschild, M.Z., Astrup, T.F., Rosenbaum, R.K.: Preparing the ground for an operational handling of long-term emissions in LCA. International Journal of LCA 20(10), 1444-1455, DOI10.1007/s11367-015-0941-4, 2015.

207 development of emission concentrations over the next 20,000 years for Cd and over 100,000 years for Cu. The 208 results of this work could be used in an LCA context, as illustrated in the same study which also presents results of 209 an LCIA. On the other hand, only information for two metals is given and the time frames for the emission 210 development are different for both metals. A different geochemical landfill model, LandSim, has also been 211 employed to predict the depletion of heavy metals (among others) from a typical municipal solid waste landfill over 212 a 20,000-years period, based on a variety of landfill parameters (Slack et al. 2007). Results of the simulation show 213 that heavy metals leach at very low concentrations over a long period of time and that only chromium and mercury 214 at any point in time exceed current drinking water standards proposed by health organizations. Moreover, the results 215 indicated that the heavy metal content remaining inside the waste mass is negligible after 4,000 years. This 216 conclusion contradicts other evidence of literature suggesting long attenuation of heavy metals in landfills but also 217 findings of laboratory tests (Flyhammar et al. 1998; Hyks et al. 2009). Therefore, the reliability of these results for 218 compiling an LCI is questionable.

A laboratory test aiming at simulating the landfill leaching process can also be found in literature (Hyks et 220 al. 2009). The test used a column percolation set-up, which applied forced infiltration of eluent in the column, filled 221 with samples from an inert landfill, in order to simulate leaching until high liquid-to solid (L/S) ratios were reached, 222 corresponding to a leaching duration of thousands of years (Hyks et al. 2009). The test was performed on samples 223 from a landfill for municipal solid waste incineration air pollution control residues, up until the L/S ratio reached 224 200-250 l/kg, in order to determine the leaching behaviour of a large variety of heavy metals. The L/S ratio could 225 then be translated into time based on site-specific landfill characteristics (Hjelmar 1990) and in this case, the total 226 simulated duration corresponds to more than 10,000 years. Results of the test showed that less than $3 \%$ of the initial 227 heavy metal mass had leached during the simulated time period of 10,000 years. This test cannot, however, be used 228 in the context of LCI as it does not cover the entire leaching time period of a landfill.

229 If a relationship between $\mathrm{pH}$ and the liquid-to-solid (L/S) ratio is established for fly ash landfills, it is

230 possible to predict $\mathrm{Al}, \mathrm{Ca}, \mathrm{Cd}, \mathrm{Ba}, \mathrm{Mg}, \mathrm{Ni}, \mathrm{Pb}, \mathrm{S}, \mathrm{Pb}, \mathrm{V}$, and $\mathrm{Zn}$ concentrations in the leachate, using $\mathrm{pH}$ as a

231 determining factor, as shown in another study (Astrup et al. 2006). Two types of incineration residues (semi-dry and 232 fly ash) were treated in batches while they were either carbonated before or they were in an uncarbonated form. The $233 \mathrm{pH}$ was measured in the batches and for each measurement, the leaching of metals and the liquid-to-solid (L/S) ratio 234 was calculated. In this way, leaching concentrations were able to be connected with the level of pH. The L/S ratio 
Cite as Bakas, I., Hauschild, M.Z., Astrup, T.F., Rosenbaum, R.K.: Preparing the ground for an operational handling of long-term emissions in LCA. International Journal of LCA 20(10), 1444-1455, DOI10.1007/s11367-015-0941-4, 2015.

235 was translated into time based on average Danish environmental conditions. Based on these assumptions, the authors

236 produced emission profiles for the selected heavy metals until an L/S ratio of 5,000 which corresponds to 100,000 to

237 250,000 years. The results show different behaviour for different metals, but also according to the type of residue

238 investigated and the presence of carbonation. Therefore, it is difficult to group metals according to their leaching 239 patterns.

240 The graphs in Figure 1 present the leaching concentration profile over time modelled using the results of

241 Astrup and co-workers for four selected metals and averaged over the two waste streams modelled (non-carbonated

242 fly ash and semi-dry residue). The model has a temporal resolution of 200 years, and therefore this study could

243 easily be used to provide a time dependent LCI for this type of landfills. The total time frame is chosen at the lower

244 end of the range, set at 100,000 years.

245 The extrapolation of information obtained through leaching tests into considerations regarding metal

246 leaching behaviours in real landfills is hindered by restriction posed in the leaching simulations in the laboratory

247 (van der Sloot et al. 1996). However, for the scope of long-term emissions where actual measurements are

248 impossible to obtain, laboratory tests are the only source of information available regarding metal leaching

249 development patterns in the distant future.

250 It is important to notice that for a very long initial stage, the concentrations of leaching metals remain at a

251 low level, but then start to rise, with $\mathrm{Ni}$ and Zn reaching their maximum predicted concentrations at the end of the

252 modelling period. This observation has important consequences when assessing potential impacts and monitoring of

253 pollution around landfill sites.

\section{$254 \quad 4$ STATE OF THE ART IN LCA}

255 The life cycle impact assessment of long-term heavy metal emissions is currently problematic. The uncertainty of

256 including heavy metal long-term emissions in toxicity assessments within LCA has been identified as a problem for

257 quite some time, from both a methodological and case-study perspective (Finnveden and Nielsen 1999; Hauschild et

258 al. 2008; Hischier et al. 2010). Many LCA studies of solid waste management systems underline the uncertainty in

259 their results stemming from the inability to accurately account for these potential impacts, while others choose to

260 ignore toxicity impacts altogether (Laurent et al. 2013a; Laurent et al. 2013b). The uncertainty discussed relates

261 mainly to modelling uncertainty (both inventory and impact modelling). However, there is also a methodological 
Cite as Bakas, I., Hauschild, M.Z., Astrup, T.F., Rosenbaum, R.K.: Preparing the ground for an operational handling of long-term emissions in LCA. International Journal of LCA 20(10), 1444-1455, DOI10.1007/s11367-015-0941-4, 2015.

262 uncertainty present which is based on the choice of time aggregation principle for the emissions (Finnveden and 263 Nielsen 1999; Udo de Haes et al. 1999).

264 Long-term emissions are currently treated in LCA either by modifications in the inventory modelling or by

265 hybrid methods adopted from other fields such as risk assessment (Hischier et al. 2010). The state of the art in the

266 inventory registration of long-term emissions is represented by Ecoinvent, which is one of the most widely used

267 LCA databases, providing inventories for many processes, including waste management (Frischknecht and Rebitzer

268 2005).

269 The Ecoinvent background report for landfills provides a comprehensive set of arguments for and against

270 inclusion of long-term emissions in the inventories and consequently in impact assessment (Doka 2009), but no

271 consensus is reached by the authors (Hischier et al. 2010).

272 Therefore, Ecoinvent inventories report both short- and long-term emissions from landfills, but their

273 inclusion or not in the impact assessment depends on whether or not the chosen impact assessment methodology

274 allows for it. Impact assessment methodologies such as CML2001, EDIP 97/2003, as well as IMPACT 2002+

275 (Hauschild and Wenzel 1997; Guinée et al. 2001a; Guinée et al. 2001b; Jolliet et al. 2003; Hauschild and Potting

276 2005) can produce differentiated impact assessment results by including or excluding long-term (beyond 100 years)

277 emissions. Other methodologies, such as Ecoindicator 99 and ReCiPe apply social perspectives reflecting the social

278 and environmental values of current generations towards future generations (Goedkoop and Spriensma 2001a;

279 Goedkoop and Spriensma 2001b; Goedkoop et al. 2009). Some of these perspectives include both short- and long-

280 term emissions and apply the same characterization factor for the two emission durations in the impact assessment.

281 A similar approach of differentiated time periods has been developed previously, by distinguishing between

282 two time periods, namely the surveyable time period (set to 100 years corresponding to the end of the methanogenic

283 phase of a typical municipal waste landfill) and the infinite time period (set to the time necessary for all emissions to

284 occur) (Finnveden 1999). The author recommends assessing potential impacts over both time periods in a full LCA,

285 since it should consider impacts from all relevant emissions, instead of the common practice of cutting off emissions 286 occurring after 100 years.

287 Several approaches have been developed beyond the LCI phase in order to tackle the issue of long-term 288 emissions’ potential impacts. These approaches aim at developing specific LCIA methodologies that estimate 289 impacts from emissions beyond a point in time (stored toxicity) (Hauschild et al. 2008), or at weighing differently 
Cite as Bakas, I., Hauschild, M.Z., Astrup, T.F., Rosenbaum, R.K.: Preparing the ground for an operational handling of long-term emissions in LCA. International Journal of LCA 20(10), 1444-1455, DOI10.1007/s11367-015-0941-4, 2015.

290 impacts from future emissions compared to current impacts (environmental discounting) (Hellweg et al. 2003). The

291 last methodology presented here functions as an intercept between LCI and LCIA by eliminating emissions beyond

292 a certain threshold. Dynamic LCIA methods that have been developed but do not address specifically emissions

293 during very long time frames are not examined here as the long-term perspective requires a special framework

294 compared to simple time differentiated approaches (Levasseur et al. 2010).

\section{$295 \quad 4.1$ Stored toxicity}

296 In order to distinguish between potential toxic impacts from short- and long-term emissions, a new impact category

297 has been proposed, which builds upon current Ecoinvent practice: the emissions occurring during the first 100 years

298 of a landfill are treated together with the emissions released from all other processes in the life cycle (Hauschild et

299 al. 2008). The emissions beyond that point in time are classified as belonging to a new impact category, named

300 stored toxicity (or stored human toxicity and stored ecotoxicity), following the EDIP 2003 method (Hauschild and

301 Potting 2005). In order to estimate the potential toxic impacts, emissions inventoried in the stored toxicity categories

302 are characterised in the same way (and based on the same factors) as in the traditional toxicity categories. The

303 characterised results are then normalised based on an area’s total annual stored toxicity, which is determined from

304 the mass flow of heavy metals within all waste streams in the year 1994, divided by the area’s population. The

305 normalization is performed in order to assess the relative magnitude of the examined system’s impact.

306 The proposed stored toxicity approach was applied in an LCA study on landfilled bottom ash and the

307 results showed that stored toxicity impacts are 325 times greater than the highest result in the traditional impact

308 categories spectrum (namely Ecotoxicity ${ }_{\text {water }}$ (Birgisdóttir 2005).

309 This approach, although in line with current practice, is still problematic since the introduced impact

310 category lacks interpretation and weighting factors needed in the comparison with potential impacts in the other

311 categories. However, it provides a first step in separating between (i) emissions occurring within a time period

312 where landfill chemistry, and therefore heavy metal emissions, is well known and monitoring or testing is possible,

313 and (ii) emissions occurring in a distant future where uncertainty in their development is high and no monitoring or

314 testing is possible.

\section{$315 \quad 4.2$ Environmental discounting}


Cite as Bakas, I., Hauschild, M.Z., Astrup, T.F., Rosenbaum, R.K.: Preparing the ground for an operational handling of long-term emissions in LCA. International Journal of LCA 20(10), 1444-1455, DOI10.1007/s11367-015-0941-4, 2015.

316 Hellweg and co-workers attempted an application of economic discounting in environmental assessment under the context of LCA (Hellweg et al. 2003). The authors based their analysis on four main arguments for environmental

318 discounting (changes in magnitude of damage, pure time preference, productivity of capital, uncertainties). These

319 arguments, based on the economic theory, can be quantified in order to produce discount rates, applied on potential

320 impacts from future emissions, so that the weight of future impacts is differentiated compared with impacts from

321 emissions occurring instantly.

322 The choice, however, of a discount rate is subjective and very decisive, and in order for it to be meaningful,

323 it needs to be close to $0(-1 \% \leq r \leq+1 \%)$. Under a higher positive discount rate, even potential impacts from

324 relatively short-term emissions (below 100 years) would practically disappear. Even in the case of low discount rates

325 the value of the discount rate is the sole most determining factor for the resulting potential impacts, because of the

326 exponential nature of discounting. The choice of a discount rate presupposes the monetization of environmental

327 impacts and depends on assumptions on the development of the future global economy, as well as value choices of

328 the LCA practitioner.

329 The adoption of moral archetypes from Cultural Theory for LCA modelling purposes (Hofstetter et al.

330 2000)could be a guide for selecting an appropriate discount rate according to the selected cultural perspective

331 (Hellweg et al. 2003). However, even within each cultural perspective the subjectivity of the choice is still not

332 eradicated which endangers the objectiveness of decisions supported by an LCA, while it has been shown that the

333 influence of an archetype choice is significant for the overall LCA results (Schryver et al. 2012).

\section{$334 \quad 4.3$ Background concentrations}

335 Another approach for tackling the issue of long-term emissions has been inspired by the field of risk assessment.

336 According to this, emissions occurring at leachate concentrations that are below the background concentration levels

337 for each heavy metal can be discarded as they cause no effect (Finnveden 1999). Therefore, it has been proposed to

338 cut off emissions of heavy metals that occur after the point in time when their concentrations fall below the

339 background concentrations (Finnveden and Huppes 1995). This approach has inspired studies related to landfill

340 aftercare period and technologies related to an effort for a fast reduction of metal leaching concentrations (Brand et

341 al. 2014).

342 This approach neglects that heavy metal emissions do not necessarily follow a decreasing trend, as 
Cite as Bakas, I., Hauschild, M.Z., Astrup, T.F., Rosenbaum, R.K.: Preparing the ground for an operational handling of long-term emissions in LCA. International Journal of LCA 20(10), 1444-1455, DOI10.1007/s11367-015-0941-4, 2015.

343 illustrated in Figure 1, and that background concentrations might not stay at the same level during the long time

344 frame considered. For some heavy metals, emissions have been shown to decrease steadily and then to increase

345 again in the future (Astrup et al. 2006). On the other hand, heavy metal background concentrations could increase

346 substantially in the future because of accumulation in specific environmental compartments (van der Voet et al.

347 2000).

348 Moreover, this approach could be considered as conflicting with the general LCA principles according to

349 which all emissions should be taken into account whether above or below thresholds (Udo de Haes et al. 1999),

350 although attempts to include background levels in LCIA can be found in literature (Hellweg et al. 2005). This holds

351 in particular in the extreme case of landfill leaching in contaminated soil where landfill emissions could potentially

352 dilute the soil pore water, thus reducing its toxicity to some extent, depending on the affected organisms and the

353 dose-response curves for the leached metal. It could, however be argued that a cut-off determined by the natural

354 background pore water concentration gives a more relevant representation of actual potential toxic impacts resulting

355 from long-term heavy metal emissions than a cut-off at an arbitrarily set time limit or an infinite time horizon, as

356 concentrations of metals below the background level have no toxic effect on the local ecosystems. Due to the natural

357 variation in soil water concentrations of metals, a high degree of site-specificity would be relevant in the modelling

358 (Lado et al. 2008).

5 COMPARISON OF DIFFERENT METHODS DEALING WITH LONG-TERM EMISSIONS

360 The LCA methods described above differ in many aspects: (i) the approaches to handling the short- and long-term

361 emissions; (ii) the respect of the time equity principle; (iii) the inclusion of subjective (value) choices in the

362 accounting of potential impacts. To investigate the importance of these differences, the different LCA approaches

363 are applied on the same emission profile of Ni leaching out of an air pollution control (APC) residues landfill. Based

364 on the assumptions on the initial content of the landfill, Ni will have leached out in about 73,000 years. The cut-off

365 of emissions after 100 years, the adoption of an infinite time horizon, the handling of emissions in a separate "stored

366 toxicity” impact category, the concept of environmental discounting and the estimation of potential impacts only

367 from emissions above the background concentrations, are all applied on the Ni profile.

368 The CF used for the analysis is estimated at $4.86 \times 10^{3} \mathrm{~m}^{3} / \mathrm{kg}_{\text {emitted to soil }} \mathrm{x}$ day and it represents the impact on

369 terrestrial ecotoxicity from an emission of Ni to soil. 
Cite as Bakas, I., Hauschild, M.Z., Astrup, T.F., Rosenbaum, R.K.: Preparing the ground for an operational handling of long-term emissions in LCA. International Journal of LCA 20(10), 1444-1455, DOI10.1007/s11367-015-0941-4, 2015.

The results of the application are shown in Figure 2. The lowest impact given by the cut-off of emissions at 100 years, and the highest impact from the negative discount rate differ by approximately eight orders of magnitude.

372 The stored ecotoxicity approach (which is practically the difference between the cut-off and the infinite time horizon

373 approaches) gives an impact around five orders of magnitude higher than the results of the cut-off approach,

374 demonstrating the significance of long-term emissions against short-term. The use of a negative discount rate, which

375 gives a higher importance to impacts occurring in the future, provides the highest results. The difference between

376 impacts with a small positive and a small negative discount rate is about five orders of magnitude, highlighting the

377 importance of the choice of discount rate, which relies on subjective criteria. The second lowest overall impact is

378 produced by the inclusion of emissions only above the background concentrations. This is because the pattern of the

379 emission profile for Ni shows a sharp increase in the leached metal only after 35,000 years and exceeding the

380 background Ni concentration after 55,000 years approximately.

A similar pattern would result from the comparison of the methods for emissions of other metals, as only

382 the magnitude would change (based on different emission levels, CFs, and background concentrations). Therefore, it

383 is safe to say that the cumulative effect of the choice of LCIA approach towards long-term emissions from all metals

384 leaching out of the landfill would be much higher.

If the results from this comparison are put in the context of a full LCIA, the selection of method becomes critical as it would potentially lead to very different decisions supported by the corresponding LCA study. For

387 example, the infinite time horizon method would lead to a dominance of toxicity impact categories over the full 388 LCIA profile (Hauschild et al. 2008).

\section{DISCUSSION}

390 The prediction of the development of emissions over time for heavy metals in landfills is shown to be difficult due

391 to hindering factors such as (i) the complexity and dynamics of landfill chemistry where many processes and the 392 waste characteristics (waste composition) influence heavy metal mobility, (ii) many different parameters (e.g. pH, 393 organic matter in the deposit) that govern metal kinetics and (iii) the inherent uncertainty when attempting to predict

394 future conditions in landfills determining the chemicals behaviour for very long time periods. Due to this

395 complexity, there is little common ground among the different methods reviewed. No study has been identified that

396 has made comprehensive use of all information available regarding the governing mechanisms of metal mobility - 
Cite as Bakas, I., Hauschild, M.Z., Astrup, T.F., Rosenbaum, R.K.: Preparing the ground for an operational handling of long-term emissions in LCA. International Journal of LCA 20(10), 1444-1455, DOI10.1007/s11367-015-0941-4, 2015.

397 instead the studies tend to focus on a selected few of these mechanisms and adopt them in the construction of a 398 prediction model.

In the LCA domain, the use of predictions of long-term emissions is limited, as the current state-of-the-art

400 either uses emissions from robust models or laboratory findings that extend to the first 100 years after deposition or

401 uses mass balance calculations to estimate the aggregated emissions over infinite time horizons. The proposed

402 approaches to account for potential impacts from long-term emissions present some interesting insights but carry

403 individual, inherent problems. An overall conclusion is that a distinction in the way potential impacts are calculated

404 for short- and long-term emissions is required.

405 None of the approaches considers the changes in environmental conditions or ecosystem equilibrium when

406 estimating future potential impacts. The CF used is the same for short- and long-term emissions, although the

407 environmental compartments receiving long-term emissions are bound to change if such long time perspectives are

408 investigated. Currently, the predominant approaches for integrating emissions over time does not allow for a time-

409 differentiated CF, although that would increase accuracy. For example, fluctuations in the soil pH would change

410 drastically the metal mobility (Richards et al. 2000), increasing or decreasing their toxic potential. The presented

411 dynamic inventory allows for investigating impacts in every future point in time and paves the way for

412 investigations regarding changing over time soil properties that influence the calculations of metal toxicity.

413 The comparison of existing LCIA approaches on the same metal emission profile shows that the resulting

414 predicted potential toxic impacts differ quite substantially, thus leading to very different assessments of the toxicity

415 potential of landfill leachate. The common practice in LCA, of cutting off emissions after 100 years, is problematic

416 as it ignores the vast majority of potential impacts, regardless of the selected approach towards long-term emissions

417 as shown in Figure 2 and supported by other studies (Huijbregts et al. 2001). However, given the importance of

418 heavy metal emissions in the total toxicity-related impacts, it is essential that a robust, accurate, and realistic

419 approach is developed so that properly informed decisions can be made based on the LCA results. A robust

420 approach needs to include an accompanying module on uncertainty in both the prediction of emissions (LCI) and the 421 subsequent toxicity modelling (LCIA), which, although very complex, is essential for putting the impact assessment 422 results into context and avoiding their over-interpretation.

423 In order to produce an accurate representation of potential impacts from long-term emissions, the changes

424 in the receiving environment need to be investigated and possibly reflected in a time-dependent toxicity CF for each 
Cite as Bakas, I., Hauschild, M.Z., Astrup, T.F., Rosenbaum, R.K.: Preparing the ground for an operational handling of long-term emissions in LCA. International Journal of LCA 20(10), 1444-1455, DOI10.1007/s11367-015-0941-4, 2015.

425 metal being emitted. This should be based on a modelling of the temporal changes in landscape properties over long426 term time frames of the environmental compartments receiving the emissions (mainly soil) and the response of the 427 exposed ecosystems, which would result in time dependent fate, exposure, and effect calculations. Site-specificity is 428 also crucial, as soil properties that affect metal toxicity, such as pH or soil organic matter, vary across the globe. On the other hand, the handling of long-term emissions should be realistic, so that only real potential toxic

430 impacts are taken into account. The inclusion of background concentrations (Birgisdóttir 2005) in a comparison with 431 the emission concentrations would disregard emissions that actually dilute existing background levels in the environment. These considerations should reflect the fact that metal emissions from landfills occur over long time

433 frames but in relatively low concentrations. These low concentrations are not currently considered, due to the 434 predominant practices of integrating emissions over time. The evolution of background levels with time can be 435 addressed by modelling different scenarios (Hellweg et al. 2005). As the background levels have a significant effect 436 on the amount of emissions contributing to toxicity, a spatially differentiated approach is required in order to capture 437 the natural variations in soil concentrations of metals in different regions (e.g. Shacklette and Boerngen 1984;

438 Herselman et al. 2005; Lado et al. 2008)

439 Some of these method elements may challenge traditional axioms of LCA specifically and sustainability in 440 general. The time equity principle, essential to the sustainability concept aiming to preserve equal development 441 chances for current and future generations, according to which all emissions from a system should be treated equally 442 regardless of the point in time at which they occur, is one of them. This principle functions well in relatively short 443 time frames (one day, one year or even a decade) since the internal and external conditions that determine the 444 potential impacts from an emission do not change substantially. However, in extreme conditions, when emissions 445 occur over a very long time frame, the time equity principle cannot hold, since the conditions determining the 446 estimation of the impacts are bound to change. Therefore, emissions occurring in different time periods should be 447 treated differently in an LCA context, by modifying accordingly the associated CFs. Some existing approaches in 448 LCIA already challenge the equity principle by explicitly applying discounting in future impacts, or differentiating 449 between impacts within a surveyable time period and future impacts (Hellweg et al. 2003; Hauschild et al. 2008). 450 Likewise, the common practice in LCA to ignore impacts from emissions occurring after a specific time frame, 451 without adequate scientific argumentation, clearly violates the time equity principle.

452 On the other hand, the involvement of background concentrations is not consistent with the general rule in 
Cite as Bakas, I., Hauschild, M.Z., Astrup, T.F., Rosenbaum, R.K.: Preparing the ground for an operational handling of long-term emissions in LCA. International Journal of LCA 20(10), 1444-1455, DOI10.1007/s11367-015-0941-4, 2015.

453 LCA of treating emissions in the same way whether above or below thresholds (Udo de Haes et al. 1999). However,

454 such an approach is necessary for producing more realistic future estimates for potential toxic impacts, but also for

455 addressing the fact that long-term emissions typically emit in low concentrations but over very long time periods.

456 Overall, it is time a consensus was reached for the issue of long-term emissions in LCA. The complexity of

457 emissions prediction, the diversity of approaches, and the inherent uncertainty lead most practitioners to ignore long-

458 term emissions altogether. On the other hand, policy makers tend to undervalue or ignore future potential impacts

459 due to pure time preference (Harvey 1994), which is not supported by environmental ethics (Hellweg et al. 2003).

460 These two factors cause a significant misrepresentation of potential toxic impacts in LCA studies involving long

461 term emissions of metals.

\section{COMPLIANCE WITH ETHICAL STANDARDS}

464 Our research does not involve any human or animal participants.

\section{REFERENCES}

Althaus H, Classen M (2005) Life Cycle Inventories of Metals and Methodological Aspects of Inventorying Material Resources in ecoinvent. Int J Life Cycle Assess 10:43-49.

Astrup T, Mosbaek H, Christensen TH (2006) Assessment of long-term leaching from waste incineration airpollution-control residues. Waste Manag 26:803-14. doi: 10.1016/j.wasman.2005.12.008

Batjes NH (2008) ISRIC-WISE Harmonized Global Soil Profile Dataset (Ver. 3.1). Rep. 2008/2, ISRIC - World Soil Information, Wageningen (with dataset)

Birgisdóttir H (2005) Life cycle assessment model for road construction and use of residues from waste incineration. Technical University of Denmark

Bolton KA, Evans LJ (1991) Elemental composition and speciation of some landfill leachates with particular reference to Cadmium. Water, Air and Soil Pol 60: 43-53

Bozkurt S, Moreno L, Neretnieks I (2000) Long-term processes in waste deposits. Sci Total Environ 250:101-21.

Bozkurt S, Moreno L, Neretnieks I (1999) Long-term fate of organics in waste deposits and its effect on metal release. Sci Total Environ 228:135-52.

Bozkurt S, Sifvert M, Moreno L, Neretnieks I (2001) The long-term evolution of and transport processes in a selfsustained final cover on waste deposits. Sci Total Environ 271:145-68. 
Cite as Bakas, I., Hauschild, M.Z., Astrup, T.F., Rosenbaum, R.K.: Preparing the ground for an operational handling of long-term emissions in LCA. International Journal of LCA 20(10), 1444-1455, DOI10.1007/s11367-015-0941-4, 2015.

Brand E, de Nijs T, Claessens J, DijkStra J, Comans R, Lieste R (2014). Development of emission testing values to assess sustainable landfill management on pilot landfills. National Institute of Public Health and the Environment, Bilthoven, the Netherlands

Christensen AG, Fischer EV, Nielsen HN, Nygaard T, Østergaard H, Lenschow SR, Sørensen H, Fuglsang IA, Larsen TH (2000) Passive soil vapor extraction of chlorinated solvents using boreholes.The Second International Conference on Remediation of Chlorinated and Recalcitrant Compdounds, Monterey, California, May 22-25, 2000

Christensen T, Kjeldsen P, Bjerg P, Jensen DL, Christensen JB, Baun A, Albrechtsen H-J, Heron G (2001) Biogeochemistry of landfill leachate plumes. Appl Geochemistry 16:659-718.

Doka G (2009) Life Cycle Inventories of Waste Treatment Services. ecoinvent report No. 13. Swiss Cent. Life Cycle Invent. Dubend.

Finnveden G (1996). Solid Waste Treatment Within the Framework of Life Cycle Assessment - Metals in Municipal Solid Waste Landfills. Int J LCA1 (2) 74-78 (1996)

Finnveden G (1999) Methodological aspects of life cycle assessment of integrated solid waste management systems. Resour Conserv Recycl 26:173-187.

Finnveden G, Huppes G (1995) Life Cycle Assessment and Treatment of Solid Waste. Proceedings of the International Workshop, Stockholm, Sweden. AFR-Report 98. Stock. Sweden AFR, Swedish EPA

Finnveden G, Albertsson A-C, Berendson J, Eriksson E, Höglund LO, Karlsson S, Sundqvist J-O (1995) Solid waste treatment within the framework of life cycle assessment. J Cleaner Prod 3 (4) 189-199

Finnveden G, Nielsen PH (1999) Long-Term Emissions from Landfills Should Not be Disregarded. Int J Life Cycle Assess 4:125-126.

Flyhammar P, Tamaddon F, Bengtsson L (1998) Heavy metals in a municipal solid waste deposition cell. Waste Manag Res 16:403-410. doi: 10.1177/0734242X9801600502

Frischknecht R, Rebitzer G (2005) The ecoinvent database system: a comprehensive web-based LCA database. J Clean Prod 13:1337-1343. doi: 10.1016/j.jclepro.2005.05.002

Goedkoop M, Heijungs R, Huijbregts M, De Schryver A, Struijs J, van Zelm R (2009) ReCiPe 2008; A life cycle impact assessment method which comprises harmonised category indicators at the midpoint and the endpoint level - Report I: Characterisation. Minist. van VROM, Den Haag

Goedkoop M, Spriensma R (2001a) The Eco-indicator 99; A damage oriented method for Life Cycle Impact Assessment - Methodology Annex. PRé Consult. Amersfoort, Netherlands

Goedkoop M, Spriensma R (2001b) The Eco-indicator 99; A damage oriented method for Life Cycle Impact Assessment - Methodology Report. PRé Consult. Amersfoort, Netherlands

Guinée J, Heijungs R (1993) A proposal for the classification of toxic substances within the framework of life cycle assessment of products. Chemosphere 26:1925-1944.

Guinée JB, Gorrée M, Heijungs R, Huppes J, Kleijn R, de Koning A, van Oers A, Sleeswijk AW, Suh S, Udo de Haes HA, de Bruijn H, van Duin R, Huijbregts MAJ, Lindeijer E, Roorda AAH, van der VenBL, Weidema B (2001a) Life cycle assessment; An operational guide to the ISO standards. Minist. Housing, Spat. Plan. Environ. Cent. Environ. Sci. (CML), Den Haag Leiden, Netherlands 
Cite as Bakas, I., Hauschild, M.Z., Astrup, T.F., Rosenbaum, R.K.: Preparing the ground for an operational handling of long-term emissions in LCA. International Journal of LCA 20(10), 1444-1455, DOI10.1007/s11367-015-0941-4, 2015.

Guinée JB, Gorrée M, Heijungs R, Huppes J, Kleijn R, de Koning A, van Oers A, Sleeswijk AW, Suh S, Udo de Haes HA, de Bruijn H, van Duin R, Huijbregts MAJ, Lindeijer E, Roorda AAH, van der VenBL, Weidema B (2001b) Life cycle assessment; An operational guide to the ISO standards - Part 3: Scientific Background. Minist. Housing, Spat. Plan. Environ. Cent. Environ. Sci. (CML), Den Haag Leiden, Netherlands

Harvey CM (1994) The reasonableness of non-constant discounting. J Public Econ 53:31-51.

Hauschild M, Olsen SI, Hansen E, Schmidt A (2008) Gone...but not away_addressing the problem of long-term impacts from landfills in LCA. Int J Life Cycle Assess 13:547-554. doi: 10.1007/s11367-008-0039-3

Hauschild MZ, Potting J (2005) Background for spatial differentiation in LCA impact assessment: The EDIP03 methodology. Environ. Proj. No. 996. Inst. Prod. Dev. Tech. Univ. Denmark

Hauschild MZ, Wenzel H (1997) Environmental Assessment of Products. Vol. 2: Scientific background. Chapman \& Hall, London, Weinheim, New York

Hellweg S, Hofstetter TB, Hungerbühler K (2003) Discounting and the Environment; Should Current Impacts be Weighted Differently than Impacts Harming Future Generations ? Int J Life Cycle Assess 8:8-18.

Hellweg S, Hofstetter TB, Hungerbühler K (2005) Time-dependent life-cycle assessment of slag landfills with the help of scenario analysis: the example of Cd and Cu. J Clean Prod 13:301-320. doi: 10.1016/j.jclepro.2004.02.016

Herselman JE, Steyn CE, Fey MV (2005) Baseline concentration of Cd, Co, Cr, Cu, Pb, Ni and Zn in surface soils of South Africa. S Afr J Sci 101:509-512

Hischier R, Weidema B, Althaus H-J, Bauer C, Doka G, Dones R, Frischknecht R, Hellweg S, Humbert S, Jungbluth N, Köllner T, Loerincik Y, Margni M, Nemecek T (2010) Implementation of Life Cycle Impact Assessment Methods; ecoinvent report No. 3, v2.2. Swiss Cent. Life Cycle Invent. Dübend.

Hjelmar O (1990) Leachate from land disposal of coal fly ash. Waste Manag Res 8:429-449.

Hofstetter P, Baumgartner T, Scholz RW (2000) Modelling the Valuesphere and the Ecosphere : Integrating the Decision Makers ’ Perspectives into LCA. Int J Life Cycle Assess 5:161-175.

Huijbregts M a, Guinée JB, Reijnders L (2001) Priority assessment of toxic substances in life cycle assessment. III: Export of potential impact over time and space. Chemosphere 44:59-65.

Huijbregts MAJ, Thissen U, Guinée JB, Jager T, Kalf D, Van de Meent D, Ragas AMJ, Sleeswijk AW, Reijnders L (2000) Priority assessment of toxic substances in life cycle assessment. Part I: Calculation of toxicity potentials for 181 substances with the nested multi-media fate, exposure and effects model USES -LCA. Chemosphere 41:541-573.

Hyks J, Astrup T, Christensen TH (2009) Long-term leaching from MSWI air-pollution-control residues: leaching characterization and modeling. J Hazard Mater 162:80-91. doi: 10.1016/j.jhazmat.2008.05.011

ISO (2006a) Environmental management:- -life cycle assessment— principles and framework. Int Stand Organ Geneva 14040:2006.

ISO (2006b) Environmental management—-life cycle assessment— requirements and guidelines. Int Stand Organ Geneva 14044:2006. 
Cite as Bakas, I., Hauschild, M.Z., Astrup, T.F., Rosenbaum, R.K.: Preparing the ground for an operational handling of long-term emissions in LCA. International Journal of LCA 20(10), 1444-1455, DOI10.1007/s11367-015-0941-4, 2015.

Jolliet O, Margni M, Charles R, Humbert S, Payet J, Rebitzer G, Rosenbaum RK (2003) IMPACT 2002+: A New Life Cycle Impact Assessment Methodology. Int J Life Cycle Assess 8:324-330.

Kjeldsen P, Barlaz MA, Rooker AP, Baun A, Ledin A, Christensen TH (2002) Present and Long-Term Composition of MSW Landfill Leachate: A Review. Crit Rev Environ Sci Technol 32:297-336. doi: $10.1080 / 10643380290813462$

Kjeldsen P, Christophersen M (2001) Composition of leachate from old landfills in Denmark. Waste Manag Res 19:249-256. doi: 10.1177/0734242X0101900306

Lado LR, Hengl T, Reuter HI (2008) Heavy metals in European soils: A geostatistical analysis of the FOREGS Geochemical database. Geoderma 148:189-199. doi: 10.1016/j.geoderma.2008.09.020

Laurent A, Bakas I, Clavreul J, Bernstad A, Niero M, Gentil E, Hauschild MZ, Christensen TH (2013) Review of LCA studies of solid waste management systems - Part I: Lessons learned and perspectives. Waste Manag. doi: 10.1016/j.wasman.2013.10.045

Laurent A, Clavreul J, Bernstad A, Bakas I, Niero M, Gentil E, Christensen TH, Hauschild MZ (2013) Review of LCA studies of solid waste management systems - Part II: Methodological guidance for a better practice. Waste Manag. doi: 10.1016/j.wasman.2013.12.004

Levasseur A, Lesage P, Margni M, Deschênes L, Samson R (2010) Considering time in LCA: dynamic LCA and its application to global warming impact assessments. Environ Sci Technol 44:3169-74. doi: 10.1021/es9030003

Owsianiak M, Rosenbaum RK, Huijbregts M a J, Hauschild MZ (2013) Addressing geographic variability in the comparative toxicity potential of copper and nickel in soils. Environ Sci Technol 47:3241-50. doi: 10.1021/es3037324

Parkhurst DL, Appelo CAJ (1999) User’s Guide to PHREEQC (Version 2)--A Computer Program for Speciation, Batch-Reaction, One Dimensional Transport, and Inverse Geochemical Calculations. Water Resour Investig Rep 99-4259.

Pettersen J, Hertwich EG (2008) Critical Review: Life-Cycle Inventory Procedures for Long-Term Release of Metals. Environ Sci Technol 42:4639-4647.

Reid C, Bécaert V, Aubertin M, Rosenbaum RK, Deschênes L (2009) Life cycle assessment of mine tailings management in Canada. J Clean Prod 17:471-479. doi: 10.1016/j.jclepro.2008.08.014

Richards BK, Steenhuis TS, Peverly JH, McBride MB (2000) Effect of sludge-processing mode , soil texture and soil pH on metal mobility in undisturbed soil columns under accelerated loading. Environ Pollut 109:327-346.

Rosenbaum RK, Bachmann TM, Gold LS, Huijbregts MAJ, Jolliet O, Juraske R, Koehler A, Larsen HF, MacLeod M, Margni M, McKone TE, Payet J, Schuhmacher M, Meent D, Hauschild MZ (2008) USEtox - the UNEPSETAC toxicity model: recommended characterisation factors for human toxicity and freshwater ecotoxicity in life cycle impact assessment. Int J Life Cycle Assess 13:532-546. doi: 10.1007/s11367-008-0038-4

Schryver AM, Humbert S, Huijbregts MAJ (2012) The influence of value choices in life cycle impact assessment of stressors causing human health damage. Int J Life Cycle Assess 18:698-706. doi: 10.1007/s11367-012-0504-x

Shacklette HT, Boerngen JG (1984) Element Concentrations in Soils and Other Surficial Materials of the Conterminous United States. US Geological Survey Professional Paper 1270 
Cite as Bakas, I., Hauschild, M.Z., Astrup, T.F., Rosenbaum, R.K.: Preparing the ground for an operational handling of long-term emissions in LCA. International Journal of LCA 20(10), 1444-1455, DOI10.1007/s11367-015-0941-4, 2015.

Singh SP, Hendry MJ (2012) Solid-Phase Distribution and Leaching Behaviour of Nickel and Uranium in a Uranium Waste-Rock Piles. Water, Air, Soil Pollut 224:1360. doi: 10.1007/s11270-012-1360-9

Slack RJ, Gronow JR, Hall DH, Voulvoulis N (2007) Household hazardous waste disposal to landfill: using LandSim to model leachate migration. Environ Pollut 146:501-9. doi: 10.1016/j.envpol.2006.07.011

Stüben D, Berner Z, Kappes B, Puchelt H (2001) Environmental monitoring of heavy metals and arsenic from AgPb-Zn mining: a case study over two millennia. Environ Monit Assess 70:181-200.

Udo de Haes HA, Jolliet O, Finnveden G, Hauschild MZ, Krewit W, Mueller-Wenk R (1999) Best Available Practice Regarding Impact Categories and Category Indicators in Life Cycle Impact Assessment. Backgr. Doc. Second Work. Gr. Life Cycle Impact Assess. SETAC-Europe. p 9

602 Van der Sloot HA, Comans RNJ, Hjelmar O (1996). Similarities in the leaching behaviour of trace contaminants 603 from waste, stabilised waste, construction materials and soils. Sci Total Environ 178:111-126

604 Van der Voet E, Guinée JB, Udo de Haes HA (2000) Heavy Metals: A Problem Solved? Kluwer, Dordrecht-Boston$605 \quad$ London

Zhao FJ, McGrath SP, Merrington G (2007) Estimates of ambient background concentrations of trace metals in soils for risk assessment. Environ Pollut 148:221-9. doi: 10.1016/j.envpol.2006.10.041

608

609
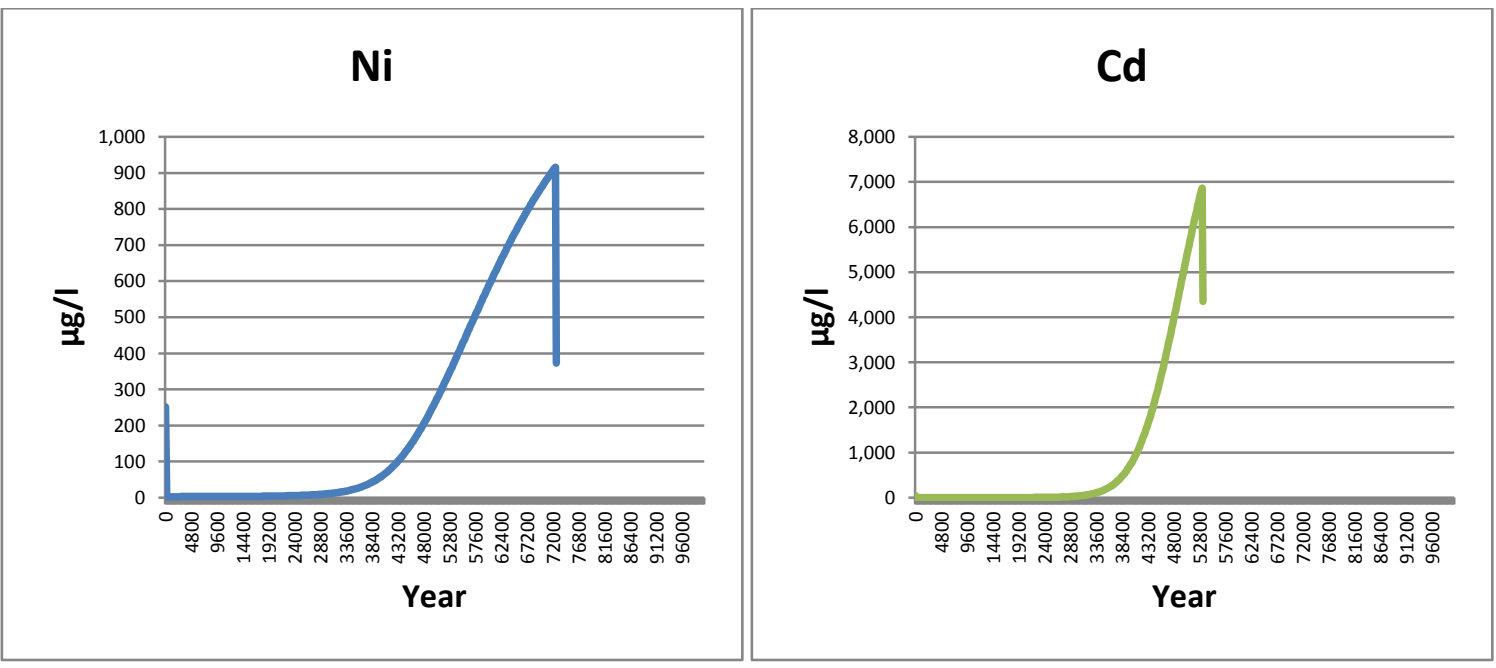
Cite as Bakas, I., Hauschild, M.Z., Astrup, T.F., Rosenbaum, R.K.: Preparing the ground for an operational handling of long-term emissions in LCA. International Journal of LCA 20(10), 1444-1455, DOI10.1007/s11367-015-0941-4, 2015.
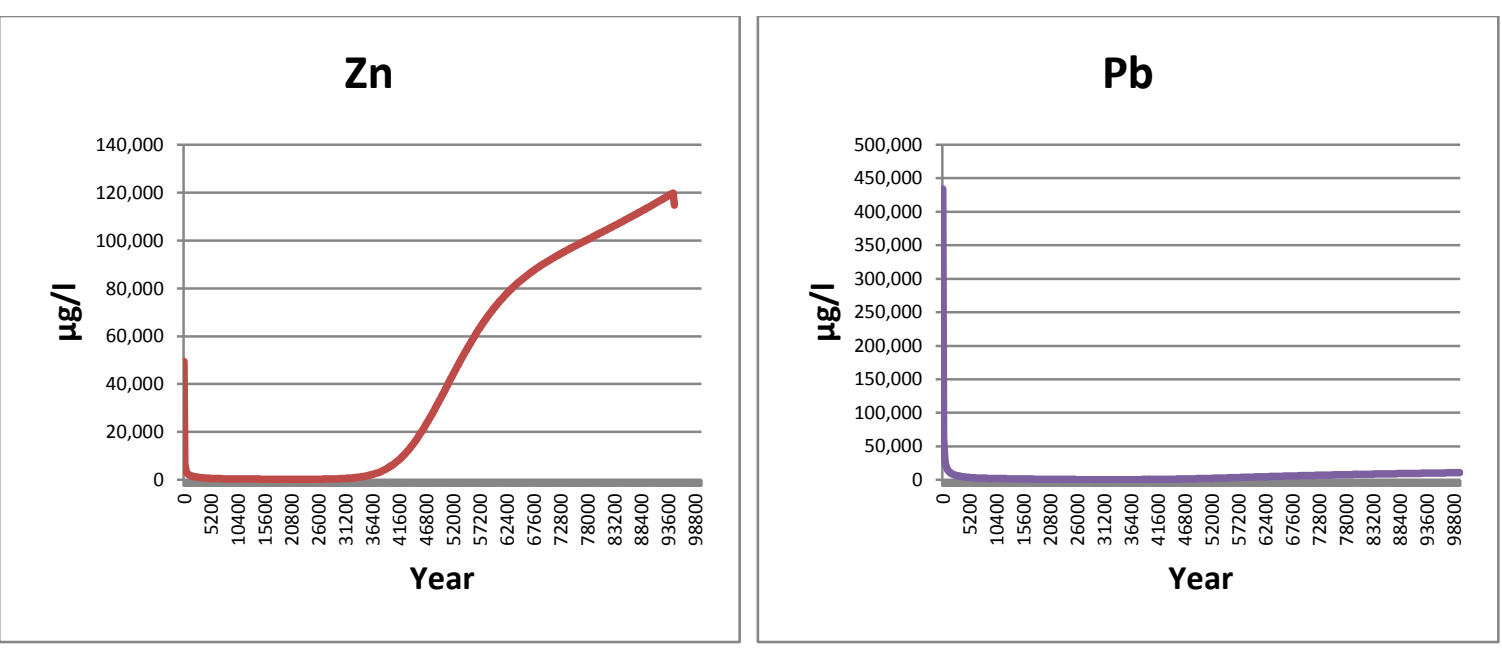

612 Figure 1. Development in average leaching concentrations for four heavy metals over 100,000 years (based on

613 Astrup et al., 2006). Note: The proposed patterns do not fully cover the time frame of 100,000 years, as the metal

614 content in the waste is depleted earlier, except for $\mathrm{Pb}$.

615

616

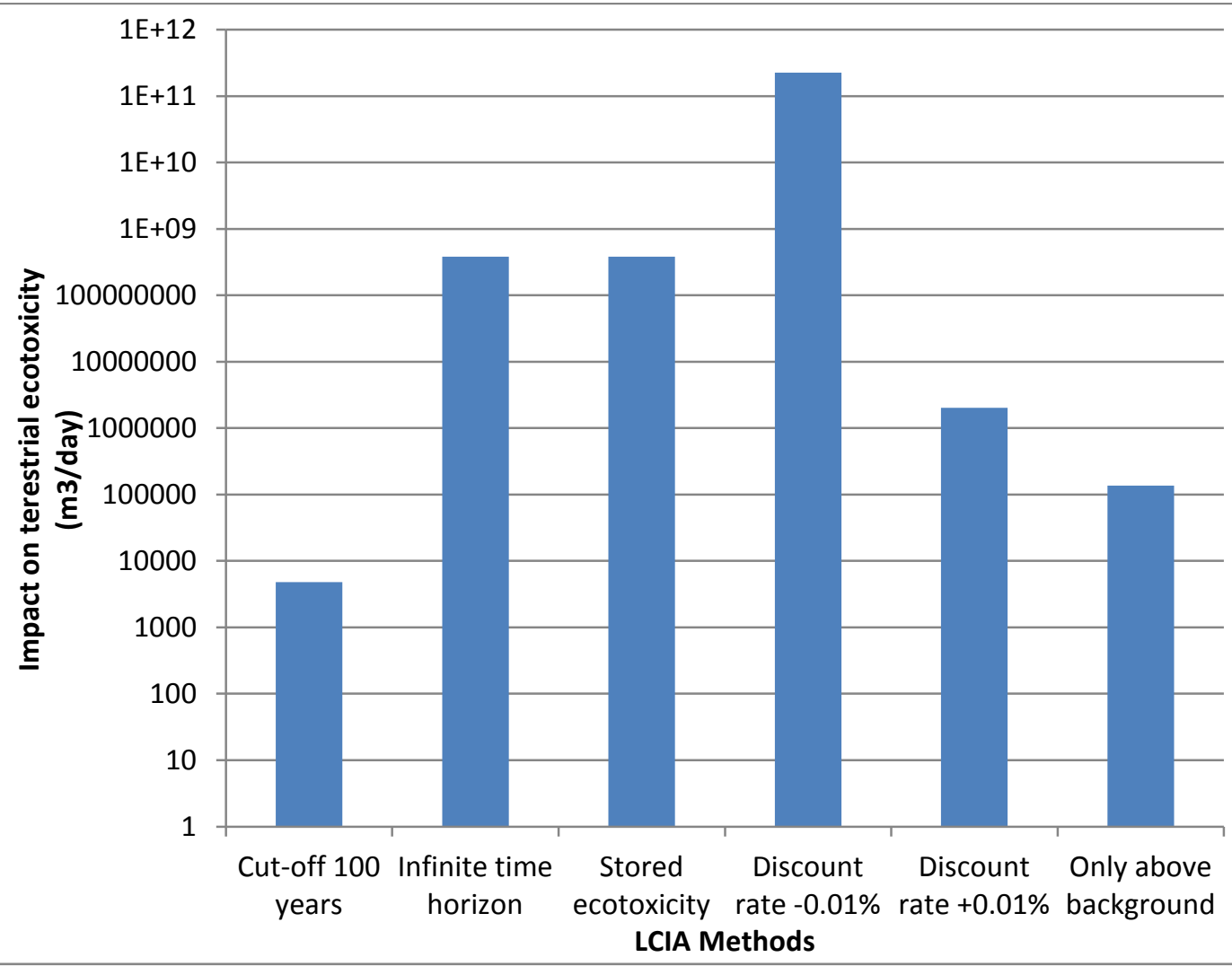


Cite as Bakas, I., Hauschild, M.Z., Astrup, T.F., Rosenbaum, R.K.: Preparing the ground for an operational handling of long-term emissions in LCA. International Journal of LCA 20(10), 1444-1455, DOI10.1007/s11367-015-0941-4, 2015.

Figure 2 Assessment of the terrestrial ecotoxicity impact for a given emission pattern of Ni leaching out of an APC residues landfill, applying five different approaches towards handling of long-term emissions 